\title{
Health behaviors, health definitions, sense of coherence, and general practitioners' attitudes towards obesity and diagnosing obesity in patients
}

\author{
Monika Bąk-Sosnowska ${ }^{1}$, Violetta Skrzypulec-Plinta ${ }^{2}$
}

${ }^{1}$ Department of Psychology, Chair of Philosophy and Humanities, School of Health Sciences, Medical University of Silesia, Katowice, Poland

2Department of Gynecological Disease Prevention and Sexology, Chair of Women's Health, School of Health Sciences, Medical University of Silesia, Katowice, Poland

Submitted: 24 June 2015

Accepted: 20 August 2015

Arch Med Sci 2017; 13, 2: 433-440

DOI: https://doi.org/10.5114/aoms.2016.58145

Copyright $\odot 2016$ Termedia \& Banach

\section{Abstract}

Introduction: Physicians' attitudes towards health may influence the motivation of patients for constructive health behaviors. The purpose of this study was to evaluate general practitioners (GP) attitudes towards health and to determine factors affecting diagnosis of obesity in their patients.

Material and methods: We examined $250 \mathrm{GPs}$. The average age was 53.55 \pm 10.57 years. We used methods examining: health behaviors (IZZ), the sense of coherence (SOC-29), the individual meaning of health (LZK), and attitude toward obesity (own questionnaire).

Results: The predominance of pro-health behaviors was found in $31.9 \%$ and anti-health behavior was observed in $24.6 \%$ of the examined group. Health was most commonly defined as a state $(74 \%)$. The most common criterion of health was "self-acceptance" (38\%). A high level of coherence was seen in $39 \%$ of individuals. A relationship between the sense of coherence and seeing health as a process $(p<0.01)$ and target $(p<0.05)$ was found in this study. We also found a relationship between the doctor's attitude towards obesity and his internship, area of residence, number of hours spent at work during the week and bodey mass index. It was found that taking the body weight and waist circumference measurements from patients depends significantly on the results from SOC-29 $(p=0.05)$ and IZZ $(p=0.05)$.

Conclusions: Polish GPs are a diverse group in terms of health behavior, defining health, sense of coherence and attitude towards obesity. High sense of coherence and the manifestation of healthy behavior are factors that favor the diagnosis of obesity in patients by the GP.

Key words: obesity, weight, general practitioners, health attitudes, health behaviors, psychological factors.

\section{Introduction}

Obesity is present in approximately $25 \%$ of Polish men and women ( $23.3 \%$ and $23.7 \%$, respectively) [1]. It is associated with the development of type 2 diabetes, hypertension and hyperlipidemia, which increase the risk of death from cardiovascular causes $[2,3]$. Despite the increase in general health awareness, the effectiveness of dealing with obesity is not satisfactory [4]. One reason could be a common perception of obesity as mainly an aesthetic problem and only then as a health problem. In Poland,

\author{
Corresponding author: \\ Monika Bąk-Sosnowska PhD \\ Department of Psychology \\ Chair of Philosophy \\ and Humanities \\ School of Health Sciences \\ Medical University \\ of Silesia \\ 12 Medyków St \\ 40-752 Katowice, Poland \\ Phone: +48 601265502 \\ E-mail: \\ b_monique@poczta.onet.pl
}


calling excess body weight directly obesity is often taken as indiscreet or even offensive. This creates a particular problem also when it comes to relations between doctors and patients. In conjunction with organizational conditions such as excessive bureaucracy as well as lack of time, this altogether can impede broaching issues associated with lifestyle during the general practitioner (GP) visit.

Because the correct body weight is one of the determinants of good health, its measurements should be a part of medical practice during the visits especially in the context of primary health care. In the case of the patient's body weight being incorrect with respect to expected weight for a particular age group, height and sex, the doctor should inform the patient about it and determine the correct procedures and in some cases refer the patient to the appropriate specialist. Taking into account the risk arising from obesity and complications associated with it, as well as many recommendations from numerous scientific societies and the Minister of Health of Poland, all adults who are 18 and above should have their body weight, height and waist circumference measurements taken every 2 years, and they should receive advice on appropriate diet and physical activity. All patients with their body mass index (BMI) above 25 or above the age of 40 should have their body weight and height measurements taken at every GP visit [5].

The cultural and social context as well as the general practitioners' attitude towards obesity and health in general can potentially influence the way in which doctors deal with patients and as a consequence the effectiveness of diagnosing and treating obesity. This means that the doctor who is motivated to take care of his own health and who maintains a healthy lifestyle will be more prone to spread those values among his patients in contrast to the doctor who is more engaged in a healthcare business only cognitively. Scientific reports confirm that the healthier the doctors' habits are, the more likely they are to advise their patients on physical activity, diet, maintaining the correct body weight, and avoiding smoking and abusing alcohol. Also, more often they take preventative actions among their patients [6-8]. The personal example of the doctor and his lifestyle as well as his awareness that he serves as a model for the promotion of health has a significant role [9].

The basis of health consists of beliefs, emotional reactions and behaviors associated with maintaining and improving one's health [10]. Health behaviors constitute an habitual, stable pattern of conduct. These include all the actions or lack of them that directly or indirectly affect human health and well-being. These can be divided into those that promote health (health-related) and threaten health (anti-health) [11]. Taking up health be- haviors is motivated via a particular definition of health. Health can be identified with the absence of disease, the general state of satisfaction or with specific values. It can be treated instrumentally or as a value within itself [12]. The attitude towards one's health results from the sense of coherence. It is a global orientation of life which consists of a sense of: comprehensibility (perceiving the environment as consistent and predictable), resourcefulness (the ability to use available resources to cope with particular demands) and meaningfulness (the belief that the actions which are undertaken are worth involvement) [13].

The aim of this study was to assess the care attitude of Polish doctors (primary care) in terms of health behaviors, attitude towards obesity, defining health, and sense of coherence, as well as to define which factors influence the doctors' diagnosis of obesity in their patients.

\section{Material and methods}

The assessed group consisted of 300 primary care doctors. The following criteria were established in order to be able to take part in the research: having a medical degree, specialization in internal medicine, general practice or pediatrics, current GP practice, permission to take part in the study. The data classified for the further analysis came from 250 people (36.4\% internists, 34\% family doctors, $29.6 \%$ pediatricians). The data from the other people were rejected due to missing information in their questionnaires, which made it impossible to carry on with the further analysis.

The study was carried out throughout Poland from June until December 2013, during the duration of a doctor's refresher course. Permission was obtained from the bioethical committee of the Medical University of Silesia in Katowice (KNW/0022/KB/131/13). The method of diagnostic survey was used. Participation in the study was voluntary and anonymous. The time for the questions was unlimited.

Four standardized questionnaires and our own survey, created especially for the purposes of this study, were used. The research tools were selected according to their usefulness in relation to the issue being examined, simplicity of use and the fact that they have been adapted to Polish standards. The Health-Related Behavior Inventory - IZZ (Inwentarz Zachowań Zdrowotnych) by Z. Juczyński is composed of 24 statements which describe the behaviors associated with health. Each statement is included in the following categories: eating habits, preventive behavior, positive mental attitude, health practice. The assessed individual selects an answer under each statement on the scale from 1 to 5 (where 1 means "almost never" and 5 means "al- 
most always"). The selected answer determines how often the examined individual respected the listed behavior in the last year. The questionnaire allows one to obtain results in each category as well as the overall score, indicating the intensity of health behaviors of the individual.

The List of Health Criteria - LKZ (Lista Kryteriów Zdrowia) by Z. Juczyński consists of 24 statements which describe different meanings of health in the physical, psychological and social dimensions. The statements are assigned to different categories, defining health as: state, target, process, property or result. The role of the examined individual is to highlight those statements which he thinks are important for the assessment of health and choose 5 which are the most important ones and rank them from most to least important when assessing health. The questionnaire allows ones to obtain the results from each category as well as the hierarchy of the 5 most important values which the examined individual associates with health.

The Life Orientation Test - SOC-29 (Sense of Coherence) by A. Antonovsky in the Polish adaptation (J. Koniarek, B. Dudek, Z. Makowska) investigates the sense of coherence which consists of three dimensions: intelligibility, resourcefulness and meaningfulness. It is formed of 29 questions which are answered by the individual on a scale from 1 to 7 (numbers 1 and 7 correspond to extreme values). Some of the questions has reversed scoring, which is taken into account during calculation of results. The questionnaire allows one to obtain results in different dimensions as well as the overall score, indicating the intensity of the sense of coherence of the individual.

\section{Statistical analysis}

Statistical analysis was carried out with the program Statistica 10, StatSoft Poland. In all statistical analyses the statistical significance level $\alpha=0.05$ was adopted ( $p$-value $<0.05$ ). Compliance with the normal distribution was checked using the Shapiro-Wilk test. Due to the fact that most of the distributions were not normal distributions, the principle of applying parametric tests was accepted. In the univariate analysis, Spearman's rank correlation test $\left(r_{s}\right)$ was applied, whereas the logistic regression model was applied for the multivariate analysis.

\section{Results}

\section{Sociodemographic characteristics of the examined group}

The average time since graduation was 28 \pm 11 years and $20 \pm 11$ years since gaining the specialization. Women represented $84 \%$ of the group. The average age was $53.55 \pm 10.57$ years.
The majority of the individuals lived in a city (87.2\%), and had a partner (85.2\%) and children (91\%). The majority were happy about their income $(62.8 \%)$.

\section{Health behaviors of the examined group (IZZ plus own survey)}

The predominance of pro-health behavior was observed in $31.9 \%$ of the examined group. The mix of behaviors of some pro-health and some anti-health characteristics occurred in $43.5 \%$ of the group. The predominance of anti-health behaviors appeared in $24.6 \%$ of the group. In order to perform further analysis the results from questionnaires were classified into pro-health (57.2\%) and anti-health (42.8\%).

The average working time of the examined group was $38.05 \pm 16.12 \mathrm{~h}$ per week, and the average sleeping time was $6.62 \pm 0.99 \mathrm{~h}$ per day. The average weight was $70.32 \pm 13.43 \mathrm{~kg}$ and average BMI was $25.53 \pm 4.16 \mathrm{~kg} / \mathrm{m}^{2} .81 .6 \%$ of the group assessed their own health state as good and $9.6 \%$ as very good. At the same time, more than half of the group (56.8\%) stated that they performed preventive examinations only sometimes or never. Every 1 in 4 (26\%) individuals stated that they never performed any physical activity, and the majority of the group (52.8\%) admitted being physically active only sometimes. The majority reported regular consumption of meals either sometimes (51.2\%) or always (21.6\%). At the same time, $52.22 \%$ of the group reported eating sweets in between meals as a form of snack. Being in a good mood most of the time in life was reported by $68 \%$, and all the time by $14 \%$ of the group.

\section{Definition of health by the examined group (LKZ)}

Most often the examined individuals see health as a state (74\%), then as a result (53.8\%), a process $(53.2 \%)$, an attribute (46.6\%) and least frequently as a target (45.3\%). The overall results do not sum up due to the ability to select more than one category. In the first five most important criteria of health, the ones that appeared to be most important for the examined group were: "self-acceptance, awareness of own abilities and weaknesses" (38\%), "feeling happy most of the time" (37\%), "feeling well" (36\%), "having all parts of the body working smoothly" (36\%), "ability to enjoy life" (36\%), and "not feeling any physical discomfort" (33\%).

\section{Sense of coherence within the examined group (SOC-29)}

A high sense of coherence was shown by $39 \%$ of the group, $60 \%$ showed an average sense 
of coherence, whereas a low sense of coherence was shown by $1 \%$. In order to perform further analysis, the results from questionnaires were split into high (39\%) and others (61\%).

\section{Attitude towards obesity within the examined group (own survey)}

Table I shows information about the actions undertaken by the examined doctors, which are associated with preventing and treating obesity in their patients.

Only some of the general practitioners measure the body weight or waist circumference of the patient at each visit. After diagnosing obesity, only half were found to inform their patient about it, and only one in every 4 (27.2\%) reported always using the word "obesity". The rest of the examined doctors describe the patient's state as: "overweight" (40.8\%), "excess body weight" (25.2\%), "excess kilograms" (3.6\%), or "fatness" (3.2\%)

Some of the examined individuals (3.6\%) do not agree that obesity is actually a form of a disease, and only $1 / 3$ (32.4\%) uses the term "treatment of obesity" when advising the patient to reduce their body mass. The rest use terms such as "losing weight" (64\%) or others (3.6\%).

The examined doctors were found to use different kinds of arguments in order to motivate their patients to reduce their body weight. The most common one is a threat in the form of: health complications $(60.4 \%)$, deterioration of social re- lations (5.2\%), lack of fitness (2.8\%), or loss of physical attractiveness (1.2\%). Less commonly, the examined doctors use positive arguments such as: "overall health improvement" $(26 \%)$ or "improved physical fitness" (4.4\%).

In the field of dietary advice the doctors tend to recommend obese patients specific diets (Figure 1). The examined doctors also suggest to their obese patients some forms of physical activities (Figure 2). The examined doctors suggest to their obese patients different ways to deal with everyday stress (Figure 3).

When the examined doctors were asked to which specialist they would refer their patient first in order to successfully reduce their body weight, they said: a dietician (76.8\%), a psychologist (7.2\%), a bariatric surgeon or other specialist (4.8\%), a cosmetologist (4.4\%), or a physiotherapist (2\%).

\section{Relationship between variables}

A positive correlation was found between the sense of coherence and the perception of health in the category of process $\left(r_{s}=0.20 ; p<0.01\right)$ and target $\left(r_{s}=0.14 ; p<0.05\right)$. Moreover, the following relationships were found:

- Doctors with longer work experience and having a specialization tend to be less open to their patients when it comes to explaining the consequences associated with excess body weight $\left(r_{s}=0.14 ; p<0.05\right)$.

- Doctors from larger towns were found to measure the body weight and waist circumference

Table I. Actions taken by the examined individuals during patient visits

\begin{tabular}{|lcccc|}
\hline Prevention and treatment of obesity & $\begin{array}{c}\text { Never } \\
\text { (\%) }\end{array}$ & $\begin{array}{c}\text { Sometimes } \\
\text { (\%) }\end{array}$ & $\begin{array}{c}\text { Often } \\
\text { (\%) }\end{array}$ & $\begin{array}{c}\text { Always } \\
\text { (\%) }\end{array}$ \\
\hline Conversations about lifestyle & 1.2 & 31.2 & 54.0 & 13.6 \\
\hline Measuring body weight and waist circumference & 10.8 & 44.8 & 37.6 & 6.8 \\
\hline Informing about excessive body weight & 2.0 & 17.2 & 30.8 & 50.0 \\
\hline Use of the term obesity & 8.0 & 27.2 & 38.8 & 26.0 \\
\hline Asking about the cause of obesity & 12.4 & 20.8 & 46.4 & 20.4 \\
\hline Asking about difficulties connected with weight loss & 6.8 & 24.0 & 48.0 & 21.2 \\
\hline Explaining the possible causes of excessive body weight & 4.0 & 21.6 & 49.6 & 24.8 \\
\hline Explaining the consequences of excessive body weight & 0.4 & 15.6 & 44.8 & 39.2 \\
\hline Recommending the reduction of body weight & 0.0 & 12.0 & 32.0 & 55.6 \\
\hline Presenting the benefits of reducing body weight & 1.6 & 14.0 & 44.4 & 40.0 \\
\hline Giving advice about diet & 3.6 & 34.4 & 32.8 & 29.2 \\
\hline Giving advice about physical activity & 4.0 & 32.4 & 48.0 & 15.6 \\
\hline Giving advice about coping with stress & 15.2 & 48.0 & 32.0 & 4.8 \\
\hline Taking the decision to treat obesity on their own & 47.6 & 27.6 & 20.8 & 4.0 \\
\hline
\end{tabular}




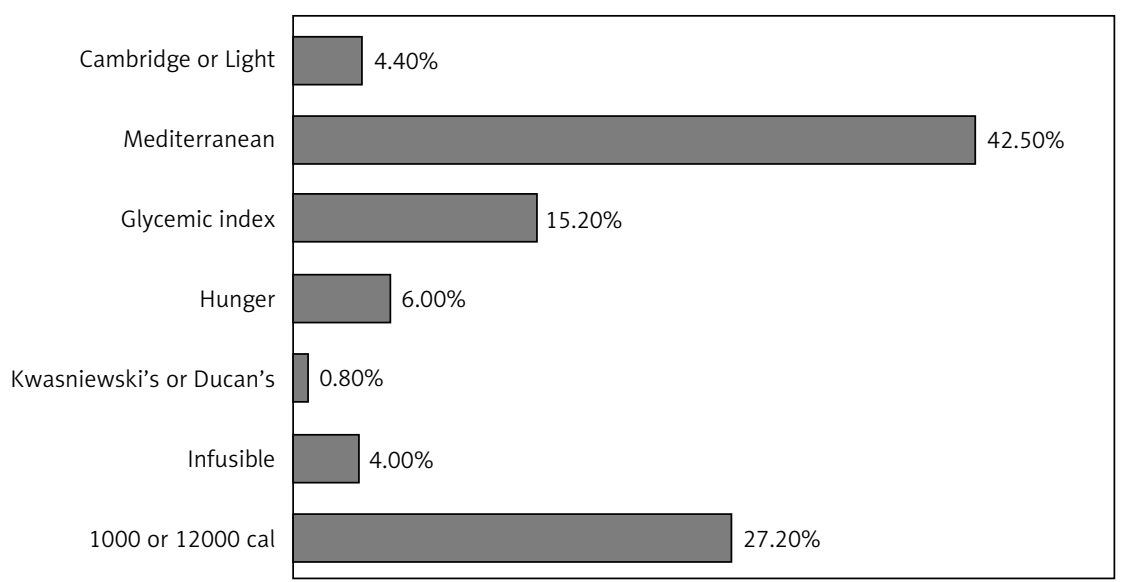

Figure 1. Diet suggested to the obese patients by the examined individuals

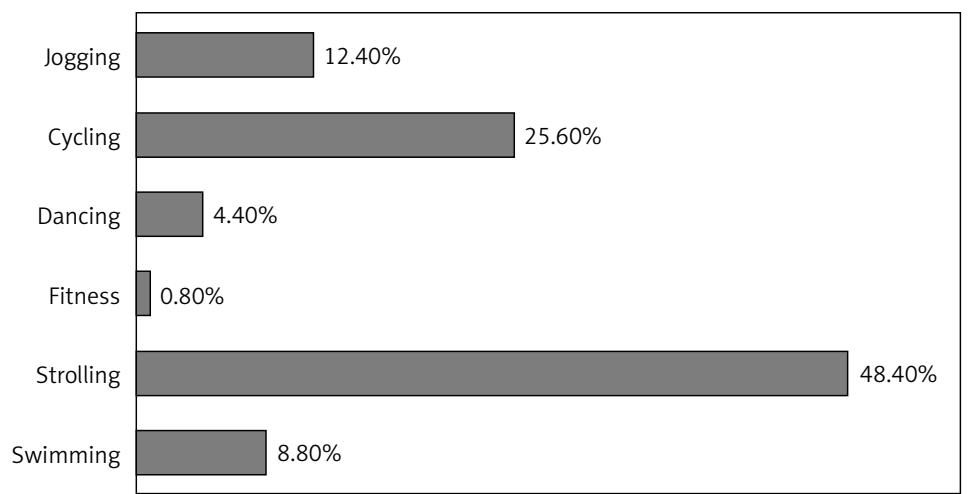

Figure 2. Physical activity suggested to the obese patients by the examined individuals

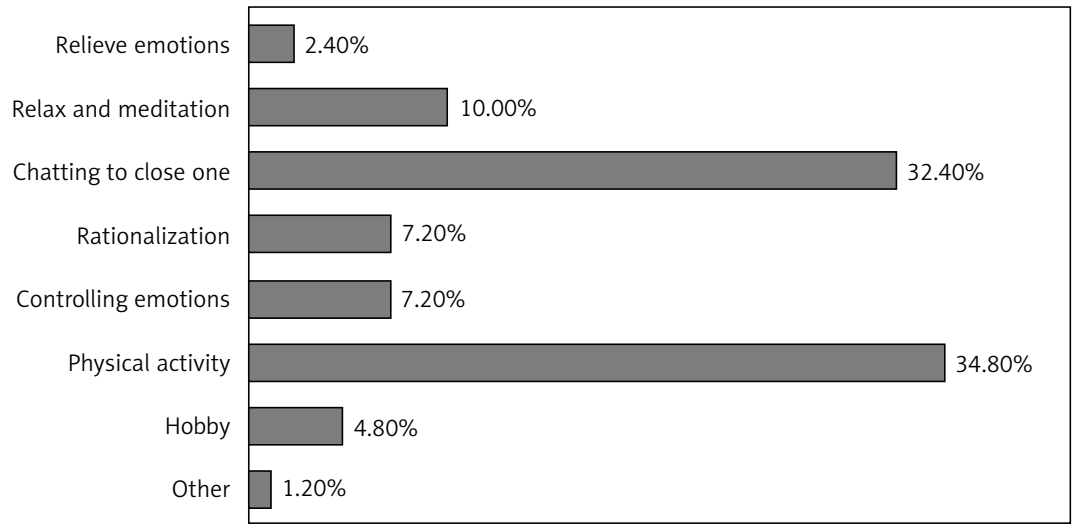

Figure 3. Methods of coping with stress suggested to the obese patients by the examined individuals

measurements of their patients less often $\left(r_{s}=-0.23 ; p<0.001\right)$, less often ask the obese patient about the causes of their obesity $\left(r_{s}=-0.13 ; p<0.05\right)$ and less often explain to the obese patient the possible causes $\left(r_{\mathrm{s}}=-0.18\right.$; $p<0.01$ ); they also less often ask the obese patient about the difficulties associated with losing the excess weight $\left(r_{s}=-0.13 ; p<0.05\right)$.

- Doctors who work longer during the week tend to more often threaten their patients with different kinds of complications associated with obesity $\left(r_{s}=0.16 ; p<0.05\right)$ and more often they present to those patients different advantages arising from losing that excess body weight $\left(r_{s}=\right.$ $0.20 ; p<0.01$ ).

- Doctors who present with higher BMI tend to more often ask their patients about the difficulties they encounter when trying to lose the excess body weight $\left(r_{s}=0.13 ; p<0.05\right)$.

In order to search for factors that contribute to the implementation of the prevention and treatment of obesity by the GPs, the results obtained from the question "Do you carry out body weight and waist circumference measurements on your 
Table II. Logistic regression analysis of factors influencing the examined doctors to make the measurement of body weight or waist circumference in their patients

\begin{tabular}{|lccccccc|}
\hline & Final score & $\begin{array}{c}\text { Standard } \\
\text { error }\end{array}$ & $\begin{array}{c}\text { Wald } \\
\text { statistic }\end{array}$ & P-value & Odds ratio & $\begin{array}{c}\text { Confidence } \\
\text { interval } \\
(-95 \%)\end{array}$ & $\begin{array}{c}\text { Confidence } \\
\text { interval } \\
(95 \%)\end{array}$ \\
\hline Free term & -0.44 & 0.51 & 0.72 & 0.3970 & 0.65 & 0.24 & 1.77 \\
\hline LKZ & 0.04 & 0.06 & 0.41 & 0.5206 & 1.04 & 1.38 & 1.05 \\
\hline SOC-29 & 0.32 & 0.14 & 5.43 & 0.0198 & 1.38 & 1.06 \\
\hline IZZ & 0.32 & 0.14 & 5.72 & 0.0168 & 1.80 \\
\hline
\end{tabular}

patients?" were dichotomized. The answer "No" was given by $56 \%$ of the examined doctors, and $44 \%$ said "Yes". The logistic regression model was built to which the following questionnaire results were incorporated; IZZ, LKZ, SOC-29. Further analysis led to the conclusion that performing the considered measurement depends significantly on SOC-29 ( $p=0.05)$ and on IZZ ( $p=0.05)$ (Table II).

The chance that the body weight and waist circumference measurements will be taken from the patient is 1.38 times more likely to be done by the physician with a high score in SOC-29 and the physician having pro-health IZZ. In the case of LKZ it was found not to be significant when performing the considered measurements.

\section{Discussion}

General practitioners are considered to be an important source of knowledge and health motivation. The advice given to the patient during the visit and in particular the doctor's own example in crease the chance for the patients to adapt to the recommendations and introduce new behaviors that will benefit their health [14]. This research showed that even though the greater proportion of doctors showed mixed health-related behaviors, in $1 / 4$ the behaviors were predominantly anti-health. Among them it is worth noting the lack of regular checkups, eating sweets in between meals and lack of physical activity. Other authors confirm that the lifestyle of Polish doctors is not significantly different from the lifestyle of the layman. The examined doctors declare that the main factors which impede implementation of healthy behaviors in patients are work schedule and family commitments $[15,16]$. Irrespective of their nationality, the most common anti-health behaviors among the doctors are: lack of sleep, rest or physical activity, alcohol abuse, unbalanced diet and lack of preventative health care $[17,18]$.

Health behaviors are considered to be an integral determinant of human health, mainly due to the prophylactic value. This research showed that even though only 1 in every 3 examined doctors seemed to present with pro-health behaviors, as many as $91 \%$ estimated their health state as good or very good. This suggests some kind of falsification of self-rated health status among the examined individuals, which may be due to several reasons: firstly, due to the conscious creation of a positive image of themselves in the healthcare environment; secondly, due to the actual lack of awareness of the state of their own health resulting from the irregular prophylactic tests; and thirdly, due to the differences in defining health.

The examined doctors defined health most often as a state and least often as a target. This means that when they were assessing their health they relied on their current feelings, not on the knowledge about their current health state or the possible divergence between the actual and desired state of health. For the most important criteria of health, the examined doctors gave answers such as self-acceptance, wellbeing and a feeling of happiness. These categories are not related to the impartial factors such as certain symptoms, but in fact they are more subjective. Medical articles about definition of health by doctors were not found in the medical database. Probably the definition of health by the WHO results in the assumption that the representatives of medical professions should understand it in a similar way, but it does not have to be synonymous with the individual perspective of particular doctors. The Polish scientist Z. Juczyński confirmed the divergence in the perception of health between doctors and people who are not related to healthcare professions. Healthcare unrelated people identified health predominantly with the correct performance of all parts of the body and the lack of physical discomfort, whereas doctors, similarly to what was found in this research, identified health as a feeling of happiness and self-acceptance [19].

In terms of the sense of coherence the examined doctors obtained results which were either average or high. Medical databases contain very few reports on the sense of coherence among doctors; more often it is evaluated in patients. A study from Austria demonstrated that GPs have a sense of coherence at the same level as other medical specializations, and at the same time it is higher than in the general population [20]. The 
relationship between the sense of coherence and the perception of health in terms of process and target which was found in this study seems to confirm the observations of other authors that people with a high sense of coherence have greater chance to be healthy and enjoy their life; they also show more pro-health behaviors $[13,21]$.

This research showed that both a high sense of coherence in GPs as well as their pro-health behaviors favor the diagnosis of obesity in the form of taking patients' body weight and waist circumference measurements. The performed study also revealed that even though most doctors inform their obese patients about their excess body weight and recommend their reduction, only some of them always record their patients' body weight. So the question is, on what basis do the doctors declare obesity in their patients? Probably the basic criterion is their appearance. However, while body size generally corresponds to body weight, this method may cause the patient's resistance and the feeling of them being judged. It was found that only $1 / 4$ of the examined doctors use the term obesity; the others tend to use non-medical terms or others which are imprecise such as overweight, which can additionally impede the patient's perception of obesity as a form of disease and can negatively influence the motivation for its treatment.

The study further showed that some doctors who advise their patients to reduce their body weight do not actually give them essential tips on how to do so. The patient has a greater chance to talk about the problems associated with obesity with a doctor who has a longer internship after obtaining a specialization, who comes from a smaller town, is not overworked and himself has a BMI above normal. This is confirmed by the reports from Lewtak and Poznańska. The authors have shown that the health education of the patients provided by the GPS is favored by the following factors: when the doctor is a woman, married, lives in a town of up to 100000 residents, has career satisfaction, has an internship of 10 years or above, is a non-smoker, pays great attention to proper nutrition, as well as having presence of some kind of chronic disease. The patients' education is not however favored by too many hours spent at work during the course of the week [22].

Knowledge of doctors about the negative consequences of obesity and effective methods of treatment is not a natural consequence of them graduating from medical schools, which is proved by many studies. For example, even though most GPs from India agreed that the reduction in body weight will bring health benefits to the obese person, simultaneously almost half of them believed that obesity only requires treatment when it is associated with other disease [23]. Similarly, most of the doctors from Saudi Arabia had a negative attitude towards obesity and assisted patients in weight reduction, but only $1 / 3$ of the examined doctors felt prepared to treat obesity themselves [24]. The vast majority of French doctors appreciated the role of physical activity in the reduction of body weight and recommended it to the obese patients, but only a few have followed the recommended level of physical activity according to any guidelines [25]. In Poland only a few percent of examined GPs were able to list the indications for surgical treatment of obesity, and more than $90 \%$ indicated the need for further training in this field [26].

This study revealed that subjective medical conditions of the doctors such as sense of coherence and defining health increase the chance to diagnose obesity in patients. The study focused on finding factors that contribute to good medical practice. The questionnaire method can be considered as a limitation in this study, due to the results being entirely based on the individuals' declarations. For obvious reasons those declarations may diverge from the actual actions taken. In addition, when searching for factors which positively influence the diagnosis of obesity, the authors focused on the selected individual variables, omitting the organizational considerations of the workplace as well as other environmental variables. The results should therefore be regarded only as a part of the complex phenomenon which includes the diagnosis and treatment of obesity by the GPs. Further research in this field should include in its analysis the addition of even more variables such as level of career satisfaction and objective data about the doctor's health state.

In conclusion, Polish GPs are a diverse group in terms of health behavior, defining health, sense of coherence and attitude towards obesity. High sense of coherence and the manifestation of healthy behavior are factors that favor the diagnosis of obesity in patients by the GP.

\section{Acknowledgments}

The authors thank Krzysztof Gojdź and Sebastian Kołodziej for technical assistance in data collection.

\section{Conflict of interest}

The authors declare no conflict of interest.

\section{References}

1. Krzysztoszek J, Wierzejska E, Zielińska A. Obesity. An analysis of epidemiological and prognostic research. Arch Med Sci 2015; 11: 24-33.

2. Stępień A, Stępień M, Wlazeł RN, Paradowski M, Banach $M$, Rysz J. Assessment of the relationship between 
lipid parameters and obesity indices in non-diabetic obese patients: a preliminary report. Med Sci Monit 2014; 20: 2683-8.

3. Zhu J, Su X, Li G, Chen J, Tang B, Yang Y. The incidence of acute myocardial infarction in relation to overweight and obesity: a meta-analysis. Arch Med Sci 2014; 10: 855-62.

4. Sumithran P, Proietto J. The defense of body weight: a physiological basis for weight regain after weight loss. Clin Sci 2013; 124: 231-41.

5. Rozporządzenie Ministra Zdrowia z dnia 21 grudnia 2004 r. w sprawie zakresu świadczeń opieki zdrowotnej, w tym badań przesiewowych, oraz okresów, w których te badania są przeprowadzane (Dz. U. 2004.276.2740). [online]. [retrieved: 16.06.2015]. Available in: http:// isap.sejm.gov.pl/DetailsServlet?id=WDU20042762740

6. Frank E, Dresner Y, Shani M, Vinker S. The association between physicians' and patients' preventive health practices. Can Med Assoc J 2013; 185: 649-53.

7. Lobelo F, Duperly J, Frank E. Physical activity habits of doctors and medical students influence their counselling practices. Br J Sports Med 2009; 43: 89-92.

8. Hung OY, Keenan NL, Fang J. Physicians' health habits are associated with lifestyle counseling for hypertensive patients. Am J Hypertens 2013; 26: 201-8.

9. Oberg EB, Frank E. Physicians' health practices strongly influence patients health practices. J R Coll Physicians Edinb 2009; 39: 290-1.

10. Bohner G, Wanke M. Postawy i zmiana postaw. GWP, Gdańsk 2004

11. Heszen I, Sęk H. Psychologia zdrowia. Wydawnictwo Naukowe PWN, Warsaw 2012; 98-101.

12. Juczyński Z. Przekonania i oczekiwania wyznacznikami zachowań związanych ze zdrowiem. In: Zasoby osobiste i społeczne sprzyjające zdrowiu jednostki. Juczyński Z, Ogińska-Bulik N (eds). Wydawnictwo Uniwersytetu Łódzkiego, Łódź 2003; 49-61.

13. Eriksson M, Lindström B. Antonovsky's sense of coherence scale and the relation with health: a systematic review. J Epidemiol Community Health 2006; 60: 376-81.

14. Saliba M, Sammut MR, Vickers KS, Celleja N. Health behaviour counselling in primary care: general practitioner - reported rate and confidence. Malta Med J 2011; 23: 22-8.

15. Cymerys M, Andrzejewska M, Nowicki M, Kałos $U$, Klimczak M. Nawyki żywieniowe lekarzy oraz osób z wyższym wyksztalceniem niemedycznym - analiza porównawcza. Endokrynol Otyłość 2009; 5: 141-2.

16. Kosteva AR, Salata BM, Krishnan SM, et al. Physician variation in perceived barriers to personal health. Int J Gen Med 2012; 5: 53-7.

17. Bazargan M, Makar M, Bazargan-Hejazi S, Ani C, Wolf KE. Preventive, lifestyle, and personal health behaviors among physicians. Acad Psychiatry 2009; 33: 289-95.

18. Dubnov-Raz G, Berry EM, Shemer O, Constantini NW. Who will take care of the caretaker? Lifestyle recommendations for physicians. Harefuah 2011; 50: 583-617.

19. Juczyński Z. Narzędzia pomiaru w promocji i psychologii zdrowia. Pacownia Testów Psychologicznych, Warsaw 2001; 106-9.

20. Siber G, Endler PC, Mesenholl E, et al. The sense of coherence among general practitioners. Wien Med Wochenschr 2009; 159: 192-5.

21. Binkowska-Bury M, Januszewicz P. Sense of coherence and health-related behaviour among university students - a questionnaire survey. Cent Eur J Pub Health 2010; 18: 145-50.
22. Lewtak K, Poznańska A. Uwarunkowania prowadzenia edukacji zdrowotnej pacjentów przez lekarzy podstawowej opieki zdrowotnej. Przegl Epidem 2012; 66: 697-704.

23. Somannavar MS, Appajigol JS. Knowledge, attitudes, and practices of public sector primary health care physicians of rural north Karnataka towards obesity management. J Family Med Prim Care 2014; 3: 400-3.

24. Alshammari Al-Shammari YF. Attitudes and practices of primary care physicians in the management of overweight and obesity in eastern Saudi Arabia. Int J Health Sci 2014; 8: 151-8.

25. Attalin V, Romain AJ, Avignon A. Physical-activity prescription for obesity management in primary care: attitudes and practices of GPs in a southern French city. Diabetes Metab 2012; 38: 243-9.

26. Giaro M, Wyleżoł M, Truszczyński O, Lewandowski T. Assessment of the knowledge of GPS considering the surgical treatment of obesity. Pol Przegl Chir 2012; 84 383-9. 